\title{
Optimizing e-learning in oncology during the COVID-19 pandemic and beyond
}

\author{
Monica Malik', Deepthi Valiyaveettil', Deepa Joseph ${ }^{2}$ \\ ${ }^{1}$ Department of Radiation Oncology, Nizam's Institute of Medical Sciences, Hyderabad, India \\ ${ }^{2}$ Department of Radiation Oncology, All India Institute of Medical Sciences, Rishikesh, India
}

Received: September 12, 2020

Revised: October 21, 2020

Accepted: October 29, 2020

Correspondence:

Deepa Joseph

Department of Radiation Oncology,

All India Institute of Medical

Sciences, Floor 6, Medical College

Building, Rishikesh 249203, India

Tel: +91-08978386509

E-mail:drdeepajoseph@yahoo.com

ORCID:

https://orcid.org/0000-0002-2970-5368
The coronavirus disease 2019 (COVID-19) pandemic has profoundly impacted cancer care, research and residency training in oncology worldwide. Many countries canceled exams, shortened their residency program and medical school tenure. Traditional teaching and learning method has faced significant disruption during this time and the situation has pushed us to adapt to e-learning. Most national and international cancer meetings were converted into a virtual platform during this time. E-learning ensures a safe environment to maintain education during a pandemic. Digital technology-based learning is likely to be used effectively in oncology training even after the pandemic ends. Stakeholders should work towards standardizing e-learning into routine educational modules and create a system of credibility and accountability.

Keywords: COVID-19, Pandemics, Learning, Oncology, Medical education

\section{Introduction}

Traditional learning in medical education is predominantly based on didactic in-person interactions with teachers, peers and patients. In residency training, besides didactic teaching, learning includes various formal and work-based formats including bedside rounds, out-patient clinics, resident-led seminars and research-based learning. Pandemics like the coronavirus disease 2019 (COVID-19) have caused significant disruption in this learning model as social distancing, team segregation and reorganization of workflow protocols take effect. This has necessitated several changes in education and training for students, residents and clinicians. Although the concept of e-learning has existed for several years, the COVID-19 pandemic has pushed digital education to the forefront of medical education.

The severe acute respiratory syndrome (SARS) outbreak in 2003 necessitated the closure of medical schools and resulted in barring of medical students from patient contact. The education of resi- dents and fellows was also severely affected in the impacted countries. The resultant severe disruption of medical education sensitized educators and policymakers to the fact that education of students and residents must continue in the face of such pandemics with all necessary safety measures [1,2].

Thus, innovative approaches such as video/audio recordings, mannequin simulators, virtual patients, webcasting and online chatrooms were successfully adopted by training programs during the outbreak. High stakes entrance and exit exams were also shifted to telephone-based or digital modules.

The COVID-19 pandemic has already caused unprecedented social and economic devastation across the globe and continues to evolve. Healthcare systems are being severely disrupted in many countries and the future course is unpredictable [3]. As September 12,2020 , more than 28 million cases have been diagnosed worldwide with over 0.9 million deaths (Johns Hopkins tracker, https:// coronavirus.jhu.edu/map.html).

Copyright (C) 2021 The Korean Society for Radiation Oncology

This is an Open Access article distributed under the terms of the Creative Commons Attribution Non-Commercial License (http://creativecommons.org/licenses/by-nc/4.0/) which permits unrestricted non-commercial use, distribution, and reproduction in any medium, provided the original work is properly cited. 
The impact on medical education, residency training and continuing medical education (CME) for providers is expected to last for a long and unpredictable duration in many countries. The ever-increasing globalization and high probability of future pandemics mandates measures and contingency plans to mitigate the impact of future pandemics on medical education.

\section{Impact on Oncology Care, Research, Education and Oncology Conferences: Need for Virtual Platform}

The rapid spread of COVID-19 has profoundly impacted cancer care globally. Cancer patients face the dual risks of acquiring the infection with a potentially higher probability of severe morbidity and mortality from COVID-19 and the adverse impact of delaying anti-cancer therapies [4]. Strict lockdowns, lack of public transport facilities and containment measures also preclude patients from access to care [5].

Measures to prevent the transmission including limiting face-toface consults, work flow modifications, delaying surgical procedures, re-distribution of oncology workforce towards other areas for pandemic control can all result in significant delays in cancer diagnosis and treatment which will ultimately impact patient outcomes.

Cancer research has suffered a significant slowdown due to the current pandemic and the impact is likely to continue for a long term [6]. Recruitment of new patients to ongoing trials have been hit due to various factors like patient reluctance, change in hospital policies into more convenient and less toxic treatment regimens and logistic reasons.

Traditional teaching in oncology is predominantly based on didactic lectures, resident-led seminars, bedside clinics, out-patient interactions and conferences with the goal of developing skills and expertise for a safe and effective workplace practice. As physical distancing norms, segregation and re-organization of teams take effect, education and training activities are likely to be severely disrupted. Infection among healthcare workers, assignment of alternative clinical responsibilities for faculty and residents, cancellation of ongoing academic programs and rescheduling or cancellation of examinations are all likely to take a toll on training and education. The unprecedented situation warrants a rapid adaptation and transition towards leveraging technology to maintain education and assessment of trainees and providers.

Most global and national meetings of various anti-cancer organizations were either re-scheduled, cancelled or changed to a virtual platform. Predominant among these were the annual meetings of the American Association of Cancer Research (AACR) which was rescheduled and changed to a virtual format and the American Society of Clinical Oncology (ASCO) which was revised to a virtual only format. The ASCO 2020 Annual Meeting was conducted in an entirely virtual format with practice changing data presented from May 29-31, 2020 and a virtual education program conducted between August 8-10, 2020. There was no registration fee for members and the fee for non-members was considerably less when compared to those of the previous meetings. The meeting had more than forty thousand participants and practice changing data and research findings from many trials and studies were presented. The virtual platform also introduced a feature for virtual networking including one-on-one chatting or video calls with other attendees, ASCO staff or industry representatives to recreate the onsite meeting experience. Registered participants also have the option to view the sessions or content at their convenience. Similarly, the Annual Meetings of European Society of Medical Oncology (ESMO) and the American Society of Radiation Oncology (ASTRO) will be conducted in a virtual format in 2020.

These are dramatic changes for organizers, presenters and attendees who are accustomed to traditional in-person conferences. Technological advances in video-conferencing and telecommunications have made these virtual meetings feasible and accessible globally. Advantages of the virtual model include significant savings of time, money and effort especially in terms of travel, accommodation and rescheduling of clinical duties. The environmental benefits of reduced greenhouse emissions from travel and hospitality can be huge. The pandemic may thus drastically alter the way scientific meetings are conducted in the future $[7,8]$. Currently, various guidelines have been proposed to assist organizers as future events are being converted to virtual or hybrid (on-site and virtual) formats $[9,10]$.

While most of the "usual business" of an onsite meeting can be shifted to the virtual platform, it would still be insufficient to recapitulate the entire experience given the missing expressions and emotions of interpersonal communication. Live presentations at these meetings represent a major avenue for professional development and career advancement for fellows and junior faculty and a virtual format may not replace this experience. The virtual formats also risk potential disruptions due to technical or connectivity issues.

\section{Current Status of E-Learning in Oncology: Modifications and Adaptations in Residency Training during Pandemics}

Technological innovations over the last two decades have enabled e-learning in many aspects of medical education. Complementary 
teaching aids such as virtual patients, video vignettes, e-learning modules, virtual three-dimensional (3D) anatomy modules and simulators are already being incorporated into medical education. These tools are highly useful aids during pandemics like the COVID-19 where they can enable uninterrupted remote learning in the face of ongoing challenges. Video-conferencing and online meeting software such as Zoom (Zoom Video Communications, San Jose, CA, USA), Webex (Cisco Webex, Milpitas, CA, USA), Skype (Skype Technologies, Palo Alto, CA, USA), GoToMeeting (LogMeln Inc., Boston, MA, USA), Teams (Microsoft Corporation, Redmond, WA, USA), Google Meet (Google, Mountain View, CA, USA), etc., with features like screen sharing, chat and video based interactions have made didactic teaching possible in a virtual classroom format. Feedback from residents and fellows has demonstrated a high degree of satisfaction and even a preference for these online teaching tools compared to traditional classroom learning. Students have reported a higher comfort less and lower inhibition and senior intimidation to interacting remotely with faculty and peers when compared to in-person teaching. In a recent study $88 \%$ of trainees felt more comfortable raising questions through videoconferencing compared to traditional didactics [11].

Tumour boards form an important component of learning and multi-disciplinary co-ordination in oncology. As tumour board discussions also transitioned to virtual formats, feedback from stakeholders suggested increasing satisfaction and a preference to continue the virtual format beyond the pandemic. The virtual model has the advantage of enhanced participation from trainees in rotation duties, those in quarantine and allows multi-centre collaboration [12].

Experience from some centres also demonstrated that e-learning, online collaborations and working during the pandemic also provided the opportunity for residents to revamp their basic medical skills and obtain important lessons in resilience, teamwork and empathy [13]. A systematic review showed a higher or similar effectiveness for e-learning compared to traditional interventions in surgical training [14]. Similarly, a long-term review of e-learning for students and resident education in otolaryngology reported higher satisfaction and significantly enhanced objective knowledge compared to traditional learning [15].

The "flipped classroom" model of blended learning incorporates interactive online lectures with discussions, under the guidance of a mentor. The study material in lecture format (audio/video) is usually shared with the participants prior to the online class so that the actual class assumes a more interactive format shifting the instruction to a learner-centric model. These formats can make learning more self-directed, less didactic and studies have shown that it is received more enthusiastically by students [16]. A me- ta-analysis of 28 studies showed an overall significant effect in favor of flipped classrooms over traditional classrooms for health professions education [17]. It also showed that incorporation of a quiz at the beginning of the class made the learning more effective.

For radiation oncology residents, better utilisation and practising on virtual environments for contouring and radiotherapy planning and evaluation can be very useful considering the shift in their work load. The ASTRO EduCase, Radiotherap-e (elntegrity e-Learning, Hertfordshire, UK), eContour, FALCON (Fellowship in Anatomic Delineation and Contouring) by the European Society for Radiotherapy and Oncology, etc., are a few examples of such virtual learning platform.

\section{Highly Interactive Technology-Based Solutions in Medical Education}

With advances in telecommunications, smartphones, point of care tools, decision making apps, mobile-based medical calculators are now in common usage by residents, fellows and providers. These devices provide real-time point of care information in bite-sized portions that can support learning and clinical care $[18,19]$. Various apps for cancer diagnosis, clinical decision support, symptom assessment, pain management, chemotherapy planning, dose calculations, drug interactions and research data collection are currently in use in oncology clinics [20]. Virtual reality (VR) simulation refers to the creation of scenarios as complex, computer-generated images. The virtual display simulates the real world and user interactions within that simulated (virtual) world. VR is being increasingly incorporated into medical education especially training in surgical and procedural skills and can prove to be a highly useful tool for learning complex procedures in cancer surgery and robotic assisted procedures [21]. Use of high-fidelity manikins with many interactive features including display of physical signs is also being adopted increasingly in medical and surgical training [22]. Wearable technologies like Google Glass can provide real-time, hands-free dynamic learning in the clinic and on-the-go $[23,24]$. Online gamebased learning offers another engaging and interactive format to enhance learning objectives and has been effectively used to improve clinical and surgical skills. It focuses on problem solving over memorizing content $[25,26]$.

\section{Advantages of E-Learning in Oncology}

A virtual learning platform can tremendously impact education of students and residents both during the pandemic and beyond as it broadens the horizons of continued education, interactive learning 
and collaboration. It will be extremely useful for faculty and trainees in any situation where physical presence is not feasible and enable learning from otherwise difficult to access experts. It can serve as a cost-effective solution for low resource settings. Digital solutions allow recording, cloud-based storage and on-demand retrieval [27]. Online learning offers the flexibility to adapt the format and content to make education more learner-centric. It makes learning active rather than passive and offers the possibility of multi-institute and even global collaborations including sharing of educational resources among organizations [28].

Studies show that "interactivity" in education is highly valued by trainees. An online learning module which offers the ability to meaningfully interact with faculty and peers and the opportunity to obtain ongoing constructive feedback is highly desirable and sustainable [29]. Pre and post session quizzes can effectively promote learner engagement and assess learning outcomes [18]. Team-based learning is an interactive teaching method that is learner centred and instructor directed. Post-lecture discussions with spaced repetitions of content in an easily digestible format can be highly effective [30]. Debate style teaching can be highly engaging for participants while providing clarity on controversial topics and multiple perspectives on clinical problems [31]. Most oncology conferences include debate-based sessions and post session audience polls which promote active participation and are effective learning opportunities. Real-time polls, chats and break-out group discussions can be highly engaging and serve to reinforce concepts. Scheduling and tracking apps can assist faculty and trainees in planning their routines and assessing their progress.

Technological solutions can also be used for ongoing mentoring of trainees and fellows and providing mental health services for physicians and trainees. E-learning has the distinct potential to revolutionize education in remote areas and community-based practices. Online assessments, practice assignments and simulation of procedures can ensure uninterrupted learning. Social media can be a powerful tool for the current and future generations to maintain ongoing education [32,33]. Digital technology can also facilitate research-based education for trainees by utilizing telemedicine to monitor patients on research protocols and video-conferencing for data monitoring and committee meetings. Online platform was successfully utilised by many academic institutes for final exit exams for the oncology residents [34].

\section{Transitioning Towards a New Era in Residency Training and Provider Education}

It is important to ensure that all potential users are familiarized with how to optimally utilize the online application. All users should also learn the basic etiquette for online conferencing including muting their microphones when not speaking, refrain from interrupting another speaker and optimal use of video and background blur for a more interactive experience. Users should also learn how to effectively moderate a session and troubleshoot minor technical issues [35]. Kotter's Change Management Model (https:// www.kotterinc.com/8-steps-process-for-leading-change/) offers insights into transitioning into, adopting and incorporating a new paradigm into routine practice [28]. A robust and sustainable modification to educational approaches is the need of the hour. Academic medical centers should prepare themselves to recognize new threats that can potentially disrupt learning. A proactive response is required that incorporates a risk-adapted approach with restructuring of academic programs to technology enabled formats without compromising continuity and quality [36]. Telemedicine can be effectively utilized for various aspects of cancer care and education [37].

\section{Challenges of E-Learning}

Major challenges include availability of infrastructure and willingness of the stakeholders to adopt the technology. Lack of time, technological skills and confidence can be a significant deterrent for teaching faculty $[38,39]$. E-learning can also be challenging in resource limited settings [40]. A negative attitude towards change and poor institutional support can preclude a successful implementation [41]. It is therefore imperative that these issues are addressed to effectively transition towards technology based learning [42]. Emotional engagement with the audience can be a challenge as facial expressions, body language and visual cues which enable real-time interpretation of participant engagement and understanding may be lacking. Besides the lack of a friendly arm and psychological support during these times of isolation and anxiety can negatively impact learning objectives. It has also been shown that distractions and disruptions can be more frequent during online learning compared to traditional classroom teaching $[43,44]$.

Fatigue of trainees could also become a significant barrier to effective learning especially when they're expected to fulfil their increased work responsibilities along with completing their learning tasks. It is also undeniable that online learning cannot replace the requirement for procedural and experiential learning although simulation [45], virtual reality, tele-consults and virtual patients can circumvent these challenges to some extent.

\section{Future Directions}

A traditional face to face teaching and learning method is un- 
doubtedly irreplaceable. But the current pandemic has steered residency training towards technologically driven learning and will provide direction and information on best practices to maintain and enhance training through these difficult times and beyond. It has provided the opportunity to leverage technology and incorporate concepts of pedagogy to the training of residents and physicians. Academic Institutes and professional societies should now focus on creating a structured and focused content to design pedagogically informed online courses which are interactive and learner-centric. The crisis can provide an impetus towards multi-institute and global collaboration in oncology training $[28,46]$.

Oncology societies like ASCO and ESMO, with their large international membership and a vast repertoire of educational resources, can take the lead in initiating and facilitating innovative approaches in learning. Over the past decade ASCO has greatly expanded its educational resources and is continuously working towards enhancing the learning experience for its members [47].

The ASCO eLearning catalogue features an increasing suite of educational resources designed to address learning needs of oncology fellows and providers (https://elearning.asco.org/).

The ESMO also provides a vast variety of educational content through the OncologyPRO section on its website (https://oncologypro.esmo.org).

Both these professional societies also have vast amount of COVID-19 related resources which are continuously updated to provide the latest updated information on oncology care during the pandemic $[48,49]$.

Future educational initiatives should leverage advances in knowledge and technology to create innovative solutions based on current concepts in cognitive learning theory. It is important to promote student engagement and minimize distraction. Interactivity and corrective feedback should be incorporated. An ongoing mechanism to access impact and effectiveness of the system will inform improvement to a dynamic and flexible system. The module should analyse learning outcomes utilizing tools for formative and summative assessments [34].

Academic institutes need to systematically plan and organize initiatives for blended learning.

Digital platforms can also be effectively utilized for objective structured teaching examination (OSTE) for a transparent assessment of teaching faculty and support career and professional development initiatives [50].

\section{Conclusion}

E-learning ensures a safe environment to maintain education during a pandemic. The enhanced audio-visual tools can be effec- tively utilized to engage learners, promote interactivity, provide feedback and assess progress. A dynamic and flexible model ensures active learning with individually tailored instruction in easily digestible bits. An effective system should also incorporate spaced repetition, practice assignments and objective assessment. Stakeholders should work towards standardizing e-learning into routine educational modules and create a system of credibility and accountability. The long-term social, environmental and professional advantages of adopting e-learning at the Institute and global level are potentially enormous. Moving forward, technology enabled learning is well poised to become an integral part of education in oncology.

\section{Conflict of Interest}

No potential conflict of interest relevant to this article was reported.

\section{References}

1. Lim EC, Oh VM, Koh DR, Seet RC. The challenges of "continuing medical education" in a pandemic era. Ann Acad Med Singap 2009;38:724-6.

2. Patil NG, Chan Y, Yan H. SARS and its effect on medical education in Hong Kong. Med Educ 2003;37:1127-8.

3. Kissler SM, Tedijanto C, Goldstein E, Grad YH, Lipsitch M. Projecting the transmission dynamics of SARS-CoV-2 through the postpandemic period. Science 2020;368:860-8.

4. Kuderer NM, Choueiri TK, Shah DP, et al. Clinical impact of COVID-19 on patients with cancer (CCC19): a cohort study. Lancet 2020;395:1907-18.

5. De Guzman R, Malik M. Dual challenge of cancer and COVID-19: impact on health care and socioeconomic systems in Asia Pacific. JCO Glob Oncol 2020;6:906-12.

6. COVID-19 Challenges Basic Researchers. Cancer Discov 2020; 10:OF3.

7. Porpiglia F, Checcucci $E$, Autorino $R$, et al. Traditional and virtual congress meetings during the COVID-19 pandemic and the postCOVID-19 era: is it time to change the paradigm? Eur Urol 2020; 78:301-3.

8. European Society of Radiology (ESR). Medical conferences in the post-COVID world: a challenge, and an opportunity. Eur Radiol 2020;30:5533-5.

9. Rubinger L, Gazendam A, Ekhtiari S, et al. Maximizing virtual meetings and conferences: a review of best practices. Int Orthop 2020;44:1461-6.

10. Spilker M, Prinsen F, Kalz M. Valuing technology-enhanced aca- 
demic conferences for continuing professional development: a systematic literature review. Prof Dev Educ 2020;46:482-99.

11. Kanneganti A, Lim KM, Chan GM, et al. Pedagogy in a pandemic: COVID-19 and virtual continuing medical education (vCME) in obstetrics and gynecology. Acta Obstet Gynecol Scand 2020; 99:692-5.

12. Dharmarajan $H$, Anderson $J L$, Kim $S$, et al. Transition to a virtual multidisciplinary tumor board during the COVID-19 pandemic: University of Pittsburgh experience. Head Neck 2020;42:1310-6.

13. Chang Liang Z, Wang W, Murphy D, Po Hui JH. Novel coronavirus and orthopaedic surgery: early experiences from Singapore. J Bone Joint Surg Am 2020;102:745-9.

14. Maertens H, Madani A, Landry T, Vermassen F, Van Herzeele I, Aggarwal R. Systematic review of e-learning for surgical training. Br J Surg 2016;103:1428-37.

15. Tarpada SP, Hsueh WD, Gibber MJ. Resident and student education in otolaryngology: a 10-year update on e-learning. Laryngoscope 2017;127:E219-24.

16. Ramnanan CJ, Pound LD. Advances in medical education and practice: student perceptions of the flipped classroom. Adv Med Educ Pract 2017;8:63-73.

17. Hew KF, Lo CK. Flipped classroom improves student learning in health professions education: a meta-analysis. BMC Med Educ 2018;18:38.

18. Bullock A, Dimond R, Webb K, Lovatt J, Hardyman W, Stacey M. How a mobile app supports the learning and practice of newly qualified doctors in the UK: an intervention study. BMC Med Educ 2015;15:71.

19. Bullock A, Webb K. Technology in postgraduate medical education: a dynamic influence on learning? Postgrad Med J 2015; 91:646-50.

20. Ana FA, Loreto MS, Jose LM, et al. Mobile applications in oncology: a systematic review of health science databases. Int J Med Inform 2020;133:104001.

21. McCloy R, Stone R. Science, medicine, and the future: virtual reality in surgery. BMJ 2001;323:912-5.

22. Ilgen JS, Sherbino J, Cook DA. Technology-enhanced simulation in emergency medicine: a systematic review and meta-analysis. Acad Emerg Med 2013;20:117-27.

23. Lamba P. Teleconferencing in medical education: a useful tool. Australas Med J 2011;4:442-7.

24. Kim S. The future of e-learning in medical education: current trend and future opportunity. J Educ Eval Health Prof 2006;3:3.

25. Graafland M, Schraagen JM, Schijven MP. Systematic review of serious games for medical education and surgical skills training. Br J Surg 2012;99:1322-30.

26. Guze PA. Using technology to meet the challenges of medical education. Trans Am Clin Climatol Assoc 2015;126:260-70.

27. Maloney $S$, Haas R, Keating JL, et al. Breakeven, cost benefit, cost effectiveness, and willingness to pay for web-based versus faceto-face education delivery for health professionals. J Med Internet Res 2012;14:e47.

28. Zuo L, Dillman D, Juve AM. Learning at home during COVID-19: a multi-institutional virtual learning collaboration. Med Educ 2020;54:664-5.

29. Wong G, Greenhalgh T, Pawson R. Internet-based medical education: a realist review of what works, for whom and in what circumstances. BMC Med Educ 2010;10:12.

30. Gaber DA, Shehata MH, Amin HA. Online team-based learning sessions as interactive methodologies during the pandemic. Med Educ 2020;54:666-7.

31. Durrani M. Debate style lecturing to engage and enrich resident education virtually. Med Educ 2020 May 11 [Epub]. https://doi. org/10.1111/medu.14217.

32. Chick RC, Clifton GT, Peace KM, et al. Using technology to maintain the education of residents during the COVID-19 pandemic. J Surg Educ 2020;77:729-32.

33. Coleman CG, Law KL, Spicer JO. \#EducationInTheTimeOfCOVID: leveraging social media to teach during the COVID-19 pandemic pandemonium. Med Educ 2020;54:852-3.

34. Boursicot $K_{1}$ Kemp S, Ong T, et al. Conducting a high-stakes OSCE in a COVID-19 environment. MedEdPublish 2020;9:54.

35. Almarzooq Zl, Lopes $\mathrm{M}$, Kochar A. Virtual learning during the COVID-19 pandemic: a disruptive technology in graduate medical education. J Am Coll Cardiol 2020;75:2635-8.

36. Ashokka B, Ong SY, Tay KH, Loh NH, Gee CF, Samarasekera DD. Coordinated responses of academic medical centres to pandemics: Sustaining medical education during COVID-19. Med Teach 2020;42:762-71.

37. Sirintrapun SJ, Lopez AM. Telemedicine in cancer care. Am Soc Clin Oncol Educ Book 2018;38:540-5.

38. O'Doherty D, Dromey M, Lougheed J, Hannigan A, Last J, McGrath D. Barriers and solutions to online learning in medical education: an integrative review. BMC Med Educ 2018;18:130.

39. Dyrbye L, Cumyn A, Day H, Heflin M. A qualitative study of physicians' experiences with online learning in a masters degree program: benefits, challenges, and proposed solutions. Med Teach 2009:31:e40-6.

40. Bediang G, Stoll B, Geissbuhler A, et al. Computer literacy and E-learning perception in Cameroon: the case of Yaounde Faculty of Medicine and Biomedical Sciences. BMC Med Educ 2013;13: 57.

41. Perlman RL, Christner J, Ross PT, Lypson ML. A successful faculty development program for implementing a sociocultural ePortfo- 
lio assessment tool. Acad Med 2014;89:257-62.

42. Bury R, Martin L, Roberts S. Achieving change through mutual development: supported online learning and the evolving roles of health and information professionals. Health Info Libr J 2006;23 Suppl 1:22-31.

43. Szpunar KK, Moulton ST, Schacter DL. Mind wandering and education: from the classroom to online learning. Front Psychol 2013:4:495.

44. Ellaway RH, Fink P, Graves L, Campbell A. Left to their own devices: medical learners' use of mobile technologies. Med Teach 2014;36:130-8.

45. Issenberg SB, McGaghie WC, Petrusa ER, Lee Gordon D, Scalese $\mathrm{RJ}$. Features and uses of high-fidelity medical simulations that lead to effective learning: a BEME systematic review. Med Teach 2005;27:10-28.

46. Murdock HM, Penner JC, Le S, Nematollahi S. Virtual Morning Report during COVID-19: a novel model for case-based teaching conferences. Med Educ 2020;54:851-2.

47. Henry NL, Patt DA, Meyers MO, et al. Bridging the medical education and quality cancer care divide: a call to action. J Oncol Pract 2015;11:424-6.

48. American Society of Clinical Oncology. COVID-19 provider \& practice information [Internet]. Alexandria, VA: American Society of Clinical Oncology; 2020 [cited 2020 Nov 10]. Available from: https://www.asco.org/asco-coronavirus-information/provider-practice-preparedness-covid-19.

49. European Society for Medical Oncology. COVID-19 and cancer [Internet]. Lugano, Switzerland: European Society for Medical Oncology; 2020 [cited 2020 Nov 10]. Available from: https:// www.esmo.org/covid-19-and-cancer?hit = ehp.

50. Fakhouri Filho SA, Nunes MDPT. Objective structured teaching examination (OSTE): an underused tool developed to assess clinical teaching skills: a narrative review of the literature. Sao Paulo Med J 2019;137:193-200. 